\title{
Evidence That Rapid Vesicle Replenishment of the Synaptic Ribbon Mediates Recovery from Short-Term Adaptation at the Hair Cell Afferent Synapse
}

\author{
Maria A. Spassova, ${ }_{1}^{1}$ Michael Avissar, ${ }^{2}$ Adam C. Furman, ${ }^{2}$ Mark A. Crumling, ${ }^{1,2}$ \\ James C. Saunders, ${ }^{1}$ and Thomas D. Parsons ${ }^{1,2}$ \\ ${ }^{1}$ Department of Clinical Studies - New Bolton Center, School of Veterinary Medicine, University of Pennsylvania, \\ Philadelphia, PA 19104, USA \\ ${ }^{2}$ Department of Otorhinolaryngology — Head and Neck Surgery, School of Medicine, University of Pennsylvania, Philadelphia, \\ PA 19104, USA
}

Received: 16 January 2004; Accepted: 4 May 2004; Online publication: 6 August 2004

\begin{abstract}
We have employed both in vitro patch clamp recordings of hair cell synaptic vesicle fusion and in vivo single unit recording of cochlear nerve activity to study, at the same synapse, the time course, control, and physiological significance of readily releasable pool dynamics. Exocytosis of the readily releasable pool was fast, saturating in less than $50 \mathrm{~ms}$, and recovery was also rapid, regaining $95 \%$ of its initial amplitude following a 200-ms period of repolarization. Longer depolarizations (greater than $250 \mathrm{~ms}$ ) yielded a second, slower kinetic component of exocytosis. Both the second component of exocytosis and recovery of the readily releasable pool were blocked by the slow calcium buffer, EGTA. Sound-evoked afferent synaptic activity adapted and recovered with similar time courses as readily releasable pool exhaustion and recovery. Comparison of readily releasable pool amplitude, capture distances of calcium buffers, and number of vesicles tethered to the synaptic ribbon suggested that readily releasable pool dynamics reflect the depletion of release-ready vesicles tethered to the synaptic ribbon and the reloading of the ribbon with vesicles from the cytoplasm. Thus, we submit that rapid recovery of the cochlear hair cell afferent fiber synapse from short-term adaptation depends on the
\end{abstract}

Correspondence to: Thomas D. Parsons - Department of Clinical Studies - New Bolton Center - University of Pennsylvania School of Veterinary Medicine • 382 West Street Road • Kennett Square, PA 19348; email: thd@vet.upenn.edu timely replenishment of the synaptic ribbon with vesicles from a cytoplasmic pool. This apparent rapid reloading of the synaptic ribbon with vesicles underscores important functional differences between synaptic ribbons in the auditory and visual systems.

Keywords: hair cell, exocytosis, adaptation, synaptic ribbon, synaptic vesicle, cochlea

\section{INTRODUCTION}

A major challenge faced by all sensory systems is to remove redundant information found in environmental cues in order to encode an efficient representation of the external world (Attneave 1954; Barlow 1961). Adaptation, a common property of sensory systems, reduces encoding redundancy by decreasing the sensitivity to constant stimulation. In the visual system, adaptation acts to optimize operating range (Koutalos and Yau 1996) and maximize information transfer (Brenner et al. 2000). Visual adaptation is mediated by a variety of different mechanisms that include modulation of the transduction cascade (Fain et al. 2001), synaptic depression (Chung et al. 2002), or activation of inhibitory ionic conductances (Carandini and Ferster 1997; Kim and Rieke 2003).

Much less is known about recovery from adaptation. Natural environments are rich with transient 
stimuli and detection of these changes is of obvious behavioral importance. The ability to detect such novel stimuli is partly limited by the rapidity with which a sensory system recovers from adaptation and sets a temporal filter for the system's response to a changing stimulus environment. Recovery from adaptation ranges from hundreds of seconds in the olfactory system (Gomez and Atema 1996), to seconds in the visual system (Palmer et al. 2003), to hundreds of milliseconds in the auditory system (Smith 1977; Harris and Dallos 1979; Chimento and Schreiner 1991). However, the cellular mechanisms required to reverse or "disadapt" an adapted sensory system are poorly understood.

Adaptation in the peripheral auditory system is likely localized to the cochlear hair cell afferent synapse because hair cell receptor potentials do not adapt to maintained acoustic stimulation (Russell and Sellick 1978; Holton and Weiss 1983). Synaptic vesicles in hair cells, like other sensory receptors and second-order neurons, are tethered at active zones to a specialized synaptic structure called a "ribbon." Similar to many other examples of calcium-dependent neurotransmitter release (Neher and Zucker 1993; Thomas et al. 1993; Bollmann et al. 2000; Schneggenburger and Neher 2000), the exocytosis of vesicles from the ribbon synapse exhibits multiple kinetic components. Such multiple components of exocytosis may be determined by distinct pools of vesicles that are defined by their molecular readiness for exocytosis or transit time from different locations in the cell to release sites. At the retinal bipolar cell, the first pool released $(\tau=1.5 \mathrm{~ms})$ matches the number of vesicles in direct contact with the presynaptic membrane (Mennerick and Matthews 1996; Neves and Lagnado 1999; Palmer et al. 2003); the second pool released $(\tau=125 \mathrm{~ms})$ corresponds to the remaining vesicles tethered to the ribbon (von Gersdorff and Matthews 1994, 1996); and the last pool activated after prolonged depolarizations corresponds to a subset of cytoplasmic vesicles (von Gersdorff and Matthews 1997; Gomis et al. 1999).

Multiple kinetic components have been reported for mouse inner hair cell exocytosis (Moser and Beutner 2000). The exhaustion of the fast component or readily releasable pool has been hypothesized to underlie a form of neural adaptation (Moser and Beutner 2000). If this is true and ribbon synapse structure-function correlates are conserved, then adaptation should reflect the exhaustion of vesicles tethered to the hair cell ribbon, and recovery from adaptation should reflect the refilling of the ribbon with synaptic vesicles. Unfortunately, in mice neither the detailed characteristics of auditory nerve adaptation nor the anatomical basis of the cochlear inner hair cell readily releasable pool is known. However, in chick, cochlear synaptic ultrastructure is well described (Martinez-Dunst et al. 1997), and auditory function is largely adultlike by the first day posthatch (Saunders et al. 1973; Rebillard and Rubel 1981). Here we examine this hypothesis in the chick by exploiting our ability to make both in vitro patch clamp recordings of hair cell synaptic vesicle fusion and in vivo single unit recordings of cochlear nerve activity in the same species.

\section{MATERIAL AND METHODS}

The methods for both in vitro experiments and in vivo experiments are similar to those previously reported (Saunders et al. 1996, Spassova et al. 2001), and thus each are described in brief.

\section{Synaptic vesicle exocytosis}

Tissue preparation. Cochlear capsules were harvested (Zidanic and Fuchs 1995) from 7-12-day-old white Leghorn chicks (G. gallus domesticus) following a protocol approved by the University of Pennsylvania IACUC. The sensory epithelium was removed and a section of it mounted in a recording chamber such that the basolateral surface of individual tall hair cells could be visualized with an upright, fixed-stage compound microscope (Axioskop, Zeiss, Germany). The recording chamber contained $\sim 320$ mOsM external saline of the following composition (in $\mathrm{mM}$ ): 154 $\mathrm{NaCl}, 6 \mathrm{KCl}, 5$ HEPES, 8 glucose, $2 \mathrm{MgCl}_{2}$, $5 \mathrm{CaCl}_{2}$, pH balanced to 7.4 with $\mathrm{NaOH}$ (after Ohmori 1984; Fuchs et al. 1988; Spassova et al. 2001; Eisen et al. 2004).

Whole-cell patch clamp recording. Individual tall hair cells were patch-clamped using tight seal recordings in whole-cell configuration (Hamill et al. 1981). Cells were voltage-clamped at a holding potential of -81 $\mathrm{mV}$, and data were collected under computer control with an EPC-9 patch clamp amplifier (HEKA Electronics, GmbH, Germany). A mean resting membrane capacitance of $5.9 \pm 0.1 \mathrm{pF} \quad(n=73)$ was recorded from tall hair cells via a mean access resistance $8.0 \pm 0.3 \mathrm{M} \Omega(n=73)$. Pipettes (KIMAX 5134502, World Precision Instruments) were coated with purple ski wax (SWIX, Norwary) to reduce their capacitance and filled with $\sim 310 \mathrm{mOsM}$ internal solution of the following composition (in $\mathrm{mM}$ ): 115 glutamic acid, $115 \mathrm{CsOH}, 20$ tetraethylammonium (TEA) chloride, $13 \mathrm{NaCl}, 10$ HEPES, $3 \mathrm{MgCl}, 5 \mathrm{Na}-$ ATP, 0.3 GTP, 0.2 EGTA, pH balanced with $\mathrm{CsOH}$ to 7.4. A liquid junction potential of $11 \mathrm{mV}$ was measured for our cesium glutamate internal solution (Spassova et al. 2001), and all voltages were corrected for this liquid junction potential. 
Changes in cell membrane capacitance $\left(\Delta C_{\mathrm{m}}\right)$ were used to monitor fusion of neurotransmittercontaining vesicles during exocytosis via the "sine + DC" mode of the EPC-9 software lock-in amplifier (Gillis 2000), with $1.25-\mathrm{kHz}$ sinusoidal command voltage ( $25 \mathrm{mV}$ peak-to-peak) that was superimposed on the holding potential of $-81 \mathrm{mV}$. The $\Delta C_{\mathrm{m}}$ were elicited by depolarizing voltage clamp steps of 50 500 -ms duration. Calcium currents were sampled at $50-\mu \mathrm{s}$ intervals and filtered at $2.9 \mathrm{kHz}$. Capacitance data were filtered and analyzed offline using IgorPro software (Wavemetrics). The $\Delta C_{\mathrm{m}}$ elicited by each depolarization were quantified as the difference in the capacitance immediately before the depolarization and that measured $100 \mathrm{~ms}$ after the end of the depolarizing pulse. This avoided any contamination of the exocytotic response by capacitive transients not associated with exocytosis (Horrigan and Bookman 1994; Debus et al. 1995). All patch clamp experiments were done at $20-22^{\circ} \mathrm{C}$, and all measurements are given as mean values \pm 1 standard error of the mean (SEM).

\section{Cochlear nerve recordings}

Animal preparation. White leghorn chicks (G. gallus domesticus) between 6 and 12 days of age were anesthetized with an intramuscular injection of $25 \%$ ethyl carbamate (Urethane) solution at a dose of $0.1 \mathrm{mg} / \mathrm{g}$ body weight. The airway was exposed to assure free breathing, and the soft tissue around the ear canal was excised to reveal fully the tympanic membrane. The surgical approach to the cochlear nerve via the recessus scala tympani has been detailed elsewhere (see, e.g., Saunders et al. 1996). Protocol for the treatment and maintenance of animals was approved by the University of Pennsylvania IACUC.

Testing conditions. The skull was secured to a head holder with dental cement and then mounted on a frame located in a sound-attenuated chamber. A heating pad and a DC halogen lamp (placed $\sim 20 \mathrm{~cm}$ from the head) maintained body temperature at $41^{\circ} \mathrm{C}$.

The ear was stimulated with a closed-field sound system consisting of an earphone (Beyer Dynamic earphone, Model DT-48, Hicksville, NY, USA) to which a sound tube (10 cm long, $5 \mathrm{~mm}$ diameter) was attached. A 0.5-mm probe-tube microphone (Etyomotic Research, Model ER-7, Elk Grove Village, IL, USA) was fitted into the sound tube, and the tube was sealed about the exposed tympanic membrane. The second harmonic of the earphone was $60-74 \mathrm{~dB}$ below the fundamental across frequencies. Output from the probe microphone was connected to the analyzer module of a frequency synthesizer (Audio Precision, Model "System One," Beverton, OR, USA) and converted to $\mathrm{dB}$ sound pressure level (SPL, relative to
$20 \mu \mathrm{Pa})$. The generator module of the synthesizer produced tonal stimuli under computer control. An automatic calibration procedure achieved a constant SPL between 0.1 and $4.0 \mathrm{kHz}$ and, by adjusting the synthesizer output voltage, different SPLs could be presented.

Recordings. Borosilicate glass microelectrodes (15$30 \mathrm{M} \Omega$ ) filled with $3 \mathrm{M} \mathrm{KCl}$ were secured to a microdriver, inserted into scala tympani, and advanced in 1$\mu \mathrm{m}$ steps. Electrical signals were amplified, connected to an oscilloscope, audio monitor, and level detector. Total discharge counts were stored on hard disk, and only well-isolated units were used for collecting data. When a responsive unit was encountered, spontaneous activity was determined from a 6-s sample of activity in the absence of sound stimulation.

Stimuli. Band-limited noise bursts served as the search stimuli. When a unit was encountered, this was changed to a tone burst. Using tone bursts, a tuning curve was then obtained for each unit as described elsewhere (Saunders et al. 1996). From the tuning curve the characteristic frequency $(\mathrm{CF})$ and $\mathrm{CF}$ threshold were determined.

Paired tone-burst data were obtained at the $\mathrm{CF}$ of each unit, at a level either 20 or $30 \mathrm{~dB}$ above the $\mathrm{CF}$ threshold. Each tone burst was $100 \mathrm{~ms}$ in duration with a 2.5-ms rise/decay time. The interval between the first and second tone burst was either 5, 10, 20, $40,80,160$, or $320 \mathrm{~ms}$. When testing a unit, the sequence of intervals was randomly presented. The paired bursts were presented at a repetition rate of 1 per second. This meant that the duration between the second tone burst and the first of the next pair, for the longest interval $(320 \mathrm{~ms})$, was $480 \mathrm{~ms}$. This interval was much longer than the time needed for recovery from adaptation, thus, the second tone burst was never an influence on the first of the next pair. A peristimulus time histogram (PSTH) of unit discharge activity, obtained with $0.3-\mathrm{ms}$ resolution, was accumulated over 100-150 paired stimulus presentations. In seven of the nine units reported, data were obtained from all seven intervals. In the remaining two units, data were collected from five and six intervals, respectively.

Analysis. The histograms for each unit were reorganized into 0.9 -ms bins and the activity in each bin was converted to spikes per second $(\mathrm{S} / \mathrm{s})$. Unit latency varied slightly with $\mathrm{CF}$, and each histogram was normalized so that the highest discharge level during the first $5 \mathrm{~ms}$ of the stimulus was placed in the same bin. This meant that individual PSTHs might be moved forward or back in time by 1 or $2 \mathrm{~ms}$ to achieve the alignment. Similarly, the maximum response during the first $5 \mathrm{~ms}$ of the second PSTH was also normalized in this manner. Synchronizing the maximum response of each histogram allowed us to 
average activity across successive 0.9 -ms bins for all nine units in each interval sampled. The SEM was also calculated for each bin. The approximately $95 \mathrm{~ms}$ of discharge activity (the rise/decay activity was removed) during the steady-state level of the stimulus were isolated and fit to a two-compartment, threeparameter, exponential decay function. From these fits the maximum response, the adapted level of activity, and the time constant were determined. The coefficient of determination $\left(r^{2}\right)$ for all the first PSTHs was 0.88 or better, while for the second PSTHs it was lower for the shorter intervals but equal to or greater than 0.82 when the second PSTHs were separated from the first by intervals longer than $40 \mathrm{~ms}$.

\section{Calculation of vesicles tethered to synaptic ribbons}

Synaptic vesicles tethered to a chick cochlear hair cell synaptic ribbon are schematized in Figure 1. Note that $D_{\text {tot }}$ defines a sphere that transects the centers of the synaptic vesicles and whose surface area ultimately limits vesicle packing density. The total number of vesicles tethered to synaptic ribbons was calculated as below, assuming a 55\% packing density of vesicles on the ribbon (Lenzi et al. 1999).

$$
V_{\mathrm{tot}}=N_{\mathrm{sr}} \times V_{\mathrm{sr}}
$$

where $N_{\mathrm{sr}}$ is the number of synaptic ribbons (dense bodies) in the cell and $V_{\text {sr }}$ is the number of vesicles tethered to a synaptic ribbon and is based on the following equations:

$$
\begin{aligned}
& D_{\mathrm{tot}}=2\left(D_{\mathrm{ves}} / 2\right)+2 L_{\mathrm{tet}}+D_{\mathrm{sr}} \\
& \mathrm{SA}_{\text {sphere }}=4 \pi\left(D_{\mathrm{tot}} / 2\right)^{2} \\
& \mathrm{SA}_{\text {hex }}=\mathrm{SA}_{\text {sphere }} \times 0.91 \\
& \mathrm{CA}_{\mathrm{ves}}=\pi\left(D_{\mathrm{ves}} / 2\right)^{2} \\
& V_{\mathrm{sr}}=0.55 \times \mathrm{SA}_{\text {hex }} / \mathrm{CA}_{\mathrm{ves}}
\end{aligned}
$$

where $D_{\text {tot }}$ is the diameter of the sphere defined by synaptic ribbon and tethered vesicles; $D_{\mathrm{ves}}$ is diameter of a synaptic vesicle; $L_{\text {tet }}$ is the length the tether between the vesicle and synaptic ribbon; $D_{\mathrm{sr}}$ is the diameter of the synaptic ribbon; $\mathrm{SA}_{\text {sphere }}$ is the surface area of the sphere defined by $D_{\text {tot }}$; $\mathrm{SA}_{\text {hex }}$ is the surface area of synaptic ribbon available to packing in a hexagonal array of spherical vesicles; and $\mathrm{CA}_{\mathrm{ves}}$ is the cross-sectional area of a vesicle.

\section{RESULTS}

Two kinetic components of chick cochlear hair cell exocytosis

Whole-cell patch clamp recordings from tall hair cells of the chick basilar papilla, the avian homolog of

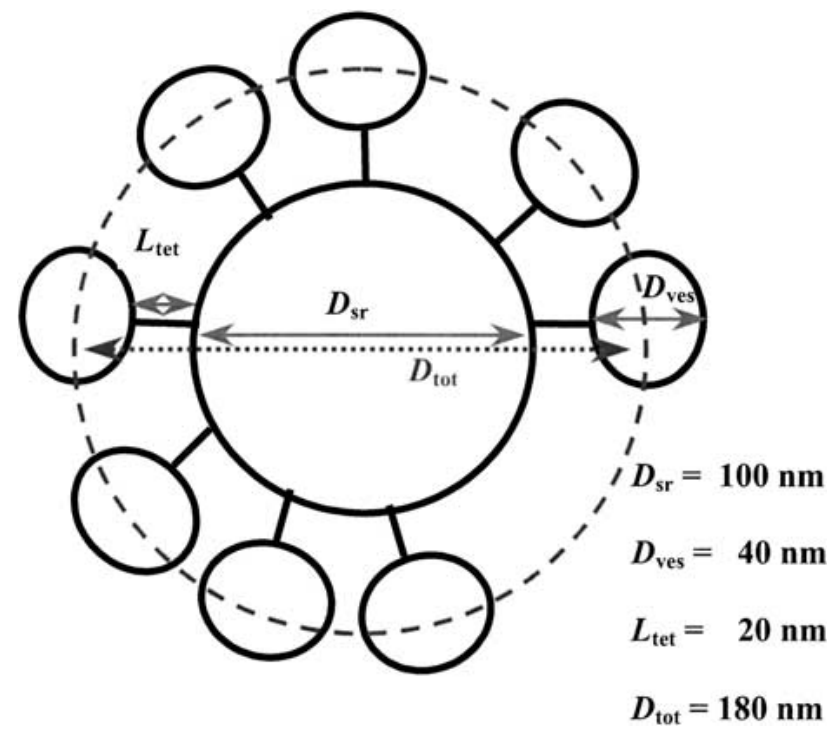

FIG. 1. Schematic of synaptic ribbon decorated with synaptic vesicles. $D_{\text {ves }}$ is the diameter of a synaptic vesicle. $L_{\text {tet }}$ is the length the tether between the vesicle and synaptic ribbon. $D_{\mathrm{sr}}$ is the diameter of the synaptic ribbon (dense body). All contribute to $D_{\text {tot }}$ the total diameter used to calculate the surface area where the synaptic vesicles have their widest circumference and contact each other. $D_{\mathrm{sr}}$ is $100 \mathrm{~nm}$ in diameter (Martinez-Dunst et al. 1997), while $L_{\text {tet }}$ and $D_{\text {ves }}$ are approximately $20 \mathrm{~nm}$ and $40 \mathrm{~nm}$, respectively (Lenzi et al. 1999). A similar mean vesicle diameter was found when we measured a sample of the vesicles found in the published electron micrograph of chick cochlear hair cells taken from the same approximate location on the basilar papilla as cells in our experiments (Martinez-Dunst et al. 1997).

mammalian cochlear inner hair cells, were used to study kinetics of calcium-dependent neurotransmitter release at the primary synapse of the auditory system. Changes in cell membrane capacitance $\left(\Delta C_{\mathrm{m}}\right)$ provided a surrogate measure of neurotransmitter release as this electrical measure of cell surface area increased following synaptic vesicle exocytosis (Parsons et al. 1994; von Gersdorff and Matthews 1994; Moser and Beutner 2000; Spassova et al. 2001). Similar to other ribbon synapses (von Gersdorff et al. 1998; Moser and Beutner 2000), the chick cochlear tall hair cell exhibits multiple kinetic components of synaptic vesicle exocytosis.

Brief depolarizing pulses elicited step increases in membrane capacitance that were independent of changes in membrane conductance or series conductance (Fig. 2A, B). A 50-ms depolarization to -21 $\mathrm{mV}$ from a holding potential of $-81 \mathrm{mV}$ resulted in a step increase in $\Delta C_{\mathrm{m}}$ that averaged $36 \pm 18 \mathrm{fF}(n=6)$. Longer depolarization pulses, up to $200 \mathrm{~ms}$ in duration, failed to elicit any further increase in cell membrane capacitance. On average, the increase in cell membrane capacitance after a 200-ms depolarization was $34 \pm 14 \mathrm{fF}(n=6)$. The clear saturation of the exocytic response across stimulus durations from 
A
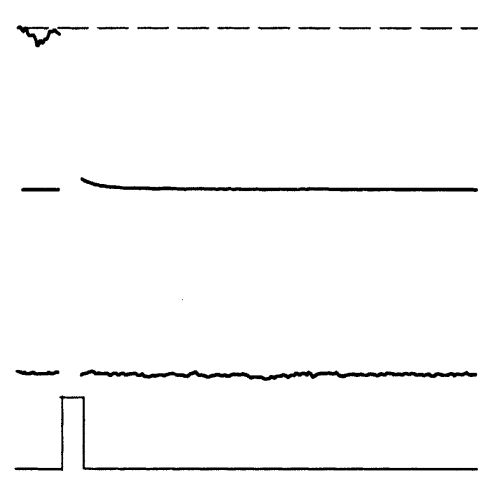

C

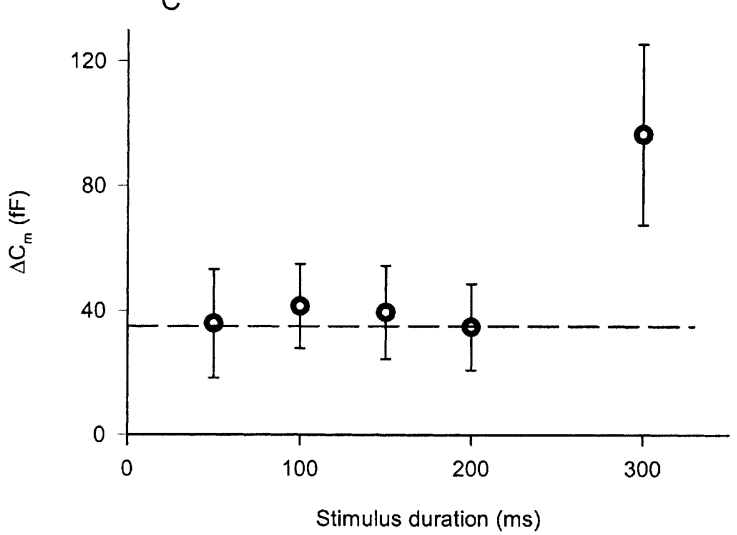

FIG. 2. Multiple kinetic components of chick cochlear hair cell exocytosis. A. Depolarizing stimulus of 100-ms duration elicits a step increase in membrane capacitance $\left(C_{\mathrm{m}}\right)$ independent of changes in membrane conductance $\left(G_{\mathrm{m}}\right)$ or series conductance $\left(G_{\mathrm{s}}\right)$. Traces are blanked during the depolarizing voltage clamp step, as the capacitance measurements are not valid due to large changes in $G_{\mathrm{m}}$ (Lindau and Neher 1988). B. A 300-ms depolarization results in a larger step change in $C_{\mathrm{m}}$. Changes in $G_{\mathrm{m}}$ also were observed. However, such changes in $G_{\mathrm{m}}$ appeared to be well separated from changes in

50 to $200 \mathrm{~ms}$ (Fig. 2C) suggested that these brief depolarizations stimulate the release of a finite pool of readily releasable vesicles (Neher 1998). Depletion of this readily releasable vesicle pool in mice cochlear inner hair cells has been postulated to underlie shortterm adaptation in the auditory nerve (Moser and Beutner 2000).

Depolarizing pulses longer than $200 \mathrm{~ms}$ evoked additional exocytosis (Fig. 2B, C), apparently activating a second kinetic component of vesicle release. On average, a 300-ms depolarization yielded a $\Delta C_{\mathrm{m}}$ of $96 \pm 29 \mathrm{fF}(n=6)$, while a $500-\mathrm{ms}$ stimulus resulted in

imulus duration (ms)
B

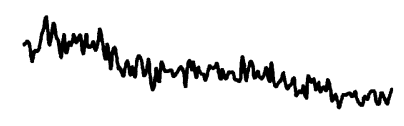

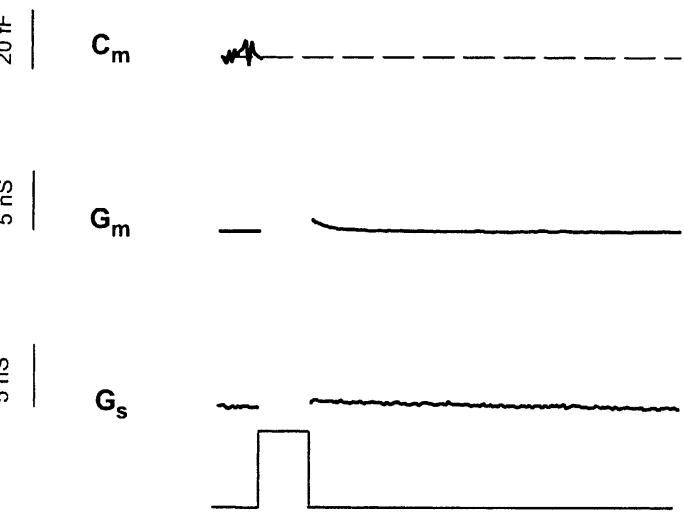

$C_{\mathrm{m}}$ by the lock-in amplifier since the increase in $G_{\mathrm{m}}$ did not correlate in magnitude or time course with the change in $C_{m}$ and likely resulted from calcium-activated channel activity (see Fig. 3). Nonetheless, capacitance traces were measured $100 \mathrm{~ms}$ after the end of the depolarizing pulse to avoid any contamination of the exocytotic response by capacitive transients not associated with exocytosis (Horrigan and Bookman 1994; Debus et al. 1995). C. The results of several experiments like $\mathbf{A}$ and $\mathbf{B}$ are summarized. The mean value and SEM os $\Delta C_{\mathrm{m}}$ are plotted versus stimulus duration.

$154 \pm 26 \mathrm{fF}(n=6)$. The second kinetic component had an initial slope of $398 \pm 71 \mathrm{fF}$-s (long-dashed line fit on Fig. 4B), several-fold slower than the initial component attributed to exocytosis of the readily releasable pool. This second kinetic component appeared to start following a delay and likely represents the activation of a second functional pool of vesicles (Neher and Zucker 1993; Thomas et al. 1993). Similar biphasic exocytic kinetics, with a delayed second component, have been previously observed at other ribbon synapses (von Gersdorff et al. 1998; Moser and Beutner 2000). 
Multiple kinetic components of exocytosis are consistent with multiple functional pools of synaptic vesicles. However, the apparent saturation of exocytosis following short depolarizations could be explained by several other possible mechanisms that include calcium channel inactivation (Wu and Saggau 1997; Forsythe et al. 1998), gating charge artifact (Horrigan and Bookman 1994), and increased endocytosis (Smith and Betz 1996). L-type calcium channels in the chick cochlear hair cell demonstrate minimal inactivation similar to several other types of hair cells (Hudspeth and Lewis 1988; Fuchs et al. 1990; Zidanic and Fuchs 1995; Rodriguez-Contreras et al. 2002; but see Schnee and Ricci 2003). On average, we have measured a $15 \% \pm 6 \%(n=7)$ decrease in calcium current amplitude after the first 80 ms of a 1-s depolarization. However, no further inactivation was observed. Thus, such a small reduction in calcium influx is not sufficient to curtail exocytosis in these cells (Spassova et al. 2001). Intracellular perfusion with a high concentration of the calcium chelator BAPTA ( $5 \mathrm{mM})$ completely blocked the increase in cell membrane capacitance (Fig. 3) without affecting the amplitude of the calcium current. On average, $\Delta C_{\mathrm{m}}$ in the presence of $5 \mathrm{mM}$ BAPTA was $6 \pm 6 \mathrm{fF}(n=5)$, whereas the calcium current under the same conditions (112 $\pm 13 \mathrm{pA}$; $n=5$ ) was unchanged from control calcium current $(112 \pm 23 \mathrm{pA} ; n=4)$. If the $\Delta C_{\mathrm{m}}$ resulted from the gating charge movement associated with activation of voltage-gated sodium or calcium channel, then, unlike synaptic vesicle exocytosis, it should be resistant to intracellular calcium chelation. Poststimulus maintenance of step increases in membrane capacitance provides no evidence for ongoing endocytosis under these recording conditions. Furthermore, our previous studies on hair cells demonstrated that whole-cell recording blocked endocytosis (Parsons et al. 1994). Similar saturation of exocytosis at other ribbon synapses (von Gersdorff and Matthews 1994; Moser and Beutner 2000) has been interpreted to reflect the exhaustion of a readily releasable pool of synaptic vesicles.

\section{Sensitivity of multiple kinetic components of exocytosis to calcium buffering}

Kinetic differences in exocytic components are often interpreted as different pools of vesicles in different states of molecular readiness (Neher and Zucker 1993; Thomas et al. 1993). These functional pools may also reflect different spatial distributions of vesicles in the cell (Parsons et al. 1995; Schikorski and Stevens 2001). To obtain evidence that the functional vesicles' pools were anatomically distinct, the properties of calcium chelators were exploited to establish

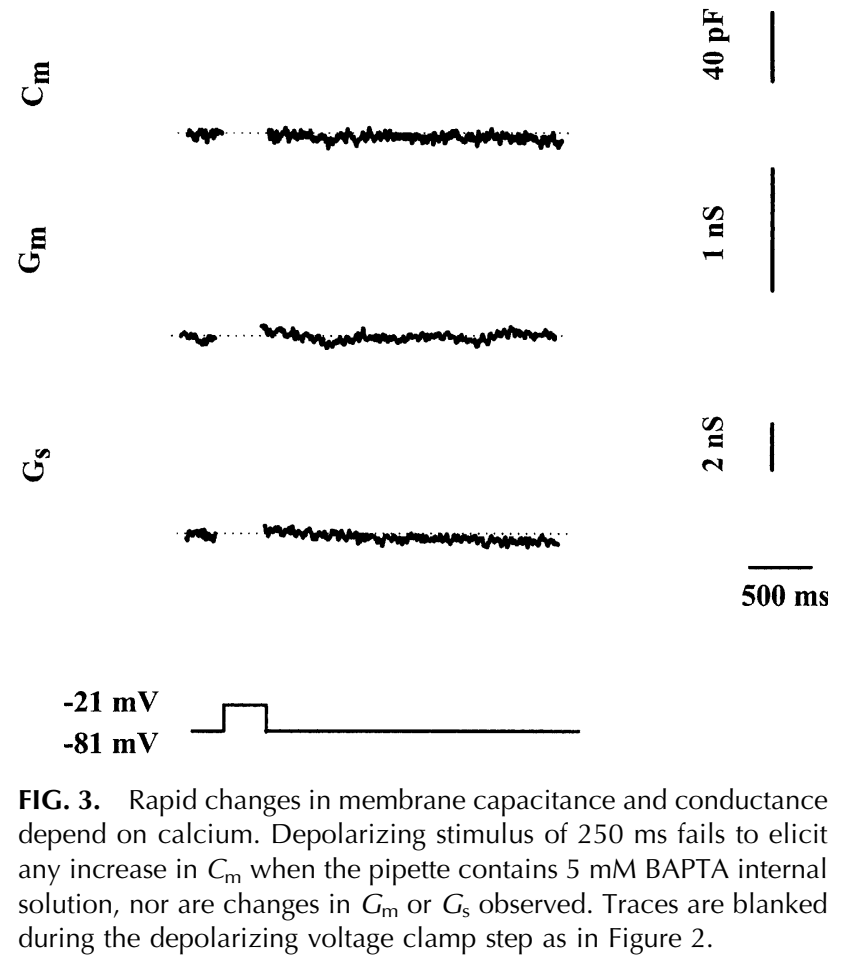

different steady-state calcium gradients within the cell. Simulations demonstrate that intracellular calcium rapidly approaches steady-state levels throughout the cell (within $<1 \mathrm{~ms}$ ) after the opening of calcium channels (Neher 1986; Roberts 1994). At steady-state, calcium concentration can be characterized with a radial exponential decay from the site of influx with a space constant:

$$
\lambda=\left(D_{\mathrm{Ca}} \tau\right)^{1 / 2}
$$

where $D_{\mathrm{Ca}}$ is the diffusion coefficient for calcium and $\tau$ is the mean capture time of the buffer and is defined by

$$
\tau=1 /\left(k_{\mathrm{on}} B\right)
$$

where $k_{\text {on }}$ is the buffer association constant, and $B$ is the buffer concentration (Roberts 1993). Accordingly, the space constant $\lambda$ of the calcium concentration can be systematically varied by using exogenous buffers with different $k_{\mathrm{on}}$ and varying their concentrations. For instance, $2.5 \mathrm{mM}$ BAPTA, $2.5 \mathrm{mM}$ EGTA, and $0.2 \mathrm{mM}$ EGTA yielded space constants of $14 \mathrm{~nm}, 300 \mathrm{~nm}$, and $1000 \mathrm{~nm}$, respectfully (Fig. 4A).

Intracellular equilibration of $2.5 \mathrm{mM}$ BAPTA or 2.5 mM EGTA was compared with the standard buffering condition of $0.2 \mathrm{mM}$ EGTA. The exogenous calcium buffers were allowed to equilibrate with the cytoplasm for 2 min prior to stimulation. When cells were perfused with a $2.5 \mathrm{mM}$ EGTA-containing internal solution, the slow component of exocytosis was selectively blocked leaving only exocytosis of the fas- 
A

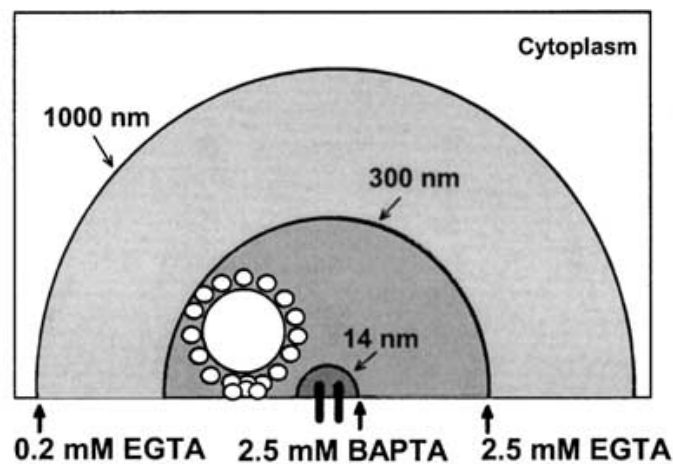

B

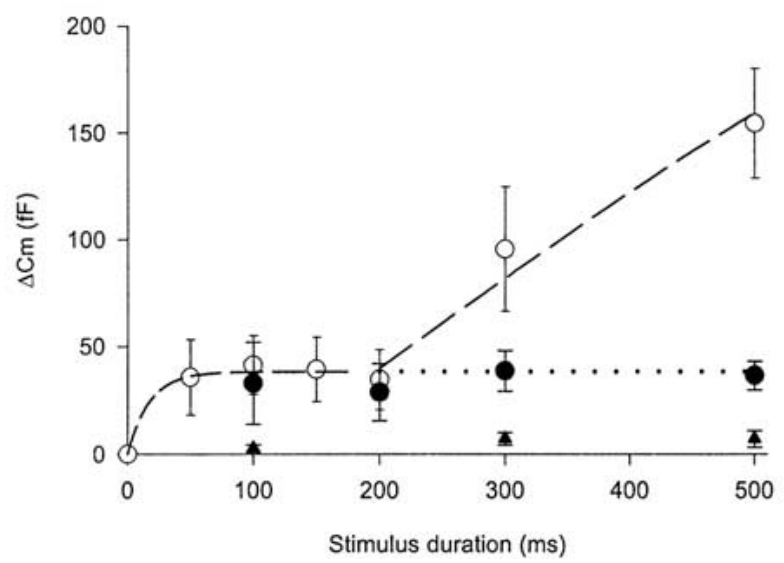

FIG. 4. Calcium buffering differentiates kinetic components of chick cochlear hair cell exocytosis. A. Schemaiic of buffer space constants of different buffer conditions and the synaptic ribbon in relation to the site of calcium influx. B. Summary of $\Delta C_{\mathrm{m}}$ versus stimulus duration for three different buffer conditions: $0.2 \mathrm{mM}$ EGTA (O) (control), $2.5 \mathrm{mM}$ EGTA $(\bullet), 2.5 \mathrm{mM}$ BAPTA $(\boldsymbol{\Delta})$. Each point on the graph represents data from a minimum of 5 cells. Long-dashed line originating at $200 \mathrm{~ms}$ has a slope of $\sim 400 \mathrm{fF} / \mathrm{s}$. The exponential curve drawn between 0 and $200 \mathrm{~ms}$ has a time constant of $29 \mathrm{~ms}$. Control data are the same as Figure $2 \mathrm{C}$ and is replotted for reader convenience.

ter component. This further defined the readily releasable pool of vesicles (Fig. 4B, filled circles). However, the same concentration of the "faster" calcium buffer BAPTA completely abolished both components of the exocytosis (Fig. 4B, filled triangles). This differential sensitivity of the kinetic components to various buffering conditions supports the notion that the multiple functional pools result from distinct spatial populations of vesicles.

Refilling of readily releasable pool is both rapid and calcium-dependent

The demands of hearing require that phasic neurotransmitter release be maintained for long periods of time (Kiang 1965). Thus, we hypothesized that the hair cell must rapidly refill its readily releasable pool to sustain neurotransmitter release. A paired-pulse paradigm was utilized to test this hypothesis. We first stimulated for $150 \mathrm{~ms}$ to exhaust the readily releasable pool and then gave a second 150 -ms pulse to probe the amount of refilling that occurred during a 200-ms recovery interval. An example of such an experiment can be seen in Figure 5A. The second pulse elicits a similarly sized capacitance jump as the first providing evidence that the readily releasable pool had refilled. On average, the amplitude of the second pulse was $95 \% \pm 5 \%(n=3)$ (Fig. $5 \mathrm{C})$ of the first and suggested that the readily releasable pool is essentially refilled in $200 \mathrm{~ms}$. In some hair cells, the refilling process proceeded even faster as we observed refilling after only $50 \mathrm{~ms}(88 \% \pm 17 \%$ refilling; $n=4)$. The increased variability in the recovery may reflect differences between cells in their ability to refill their readily releasable pool on such short time scales.

We next examined the source of vesicles that rapidly refill the readily releasable pool and asked whether the slow kinetic component reflected the mobilization of vesicles to the readily releasable pool. The refilling of the readily releasable pool was tested under conditions that block the activation of the slow component of exocytosis. Cells were internally perfused with $2.5 \mathrm{mM}$ EGTA and then subjected to the same paired pulse paradigm used above. Exocytosis of the readily releasable pool was normal; however, its recovery was inhibited (Fig. 5B). On average, $2.5 \mathrm{mM}$ EGTA blocked the refilling of the small pool by $91 \%$ $(9 \% \pm 9 \%$ refilling, $n=4)$ (Fig. 5C). Thus, rapid refilling of the readily releasable pool is calciumdependent as increased calcium buffering blocks it. These results are consistent with the notion that the rapid refilling of the readily releasable pool and the slow kinetic component of exocytosis share a common anatomical substrate.

Rapid refilling of readily releasable pool mediates recovery from short-term adaptation

At the primary auditory nerve fiber, adaptation occurs on many different time scales, referred to as rapid, short-term, long-term, or very-long-term, and spans time courses from milliseconds to minutes (Westerman and Smith 1984; Yates et al. 1985; Chimento and Schreiner 1991; Javel 1996). Previous work (Furukawa et al. 1982; Westerman and Smith 1984; Moser and Beutner 2000) suggested that the exhaustion of the readily releasable pool of vesicles in the hair cell mediates short-term adaptation in the auditory nerve. Accordingly, the rapid refilling of the readily releasable pool should determine recovery 
A
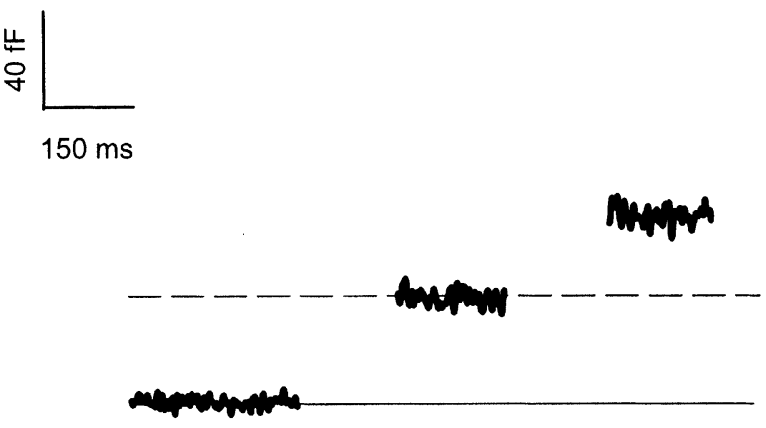

$-21 \mathrm{mV}$

$-81 \mathrm{mV}$

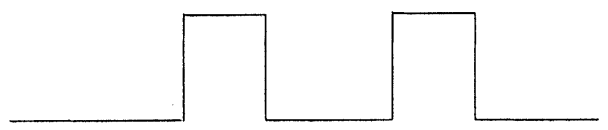

B
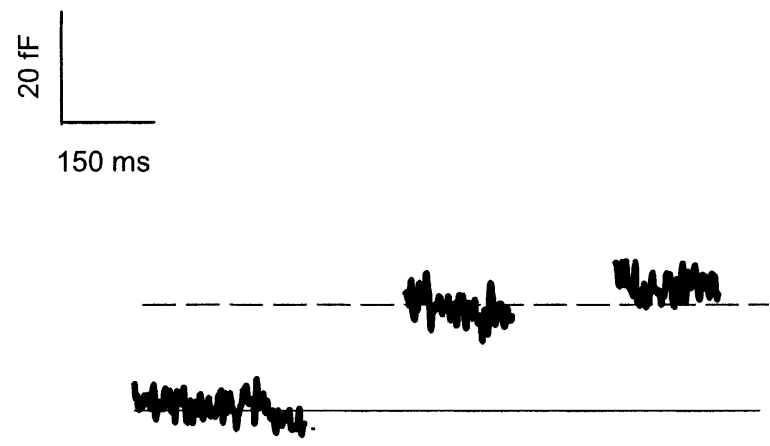

$-21 \mathrm{mV}$

$-81 \mathrm{mV}$

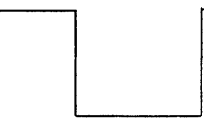

C

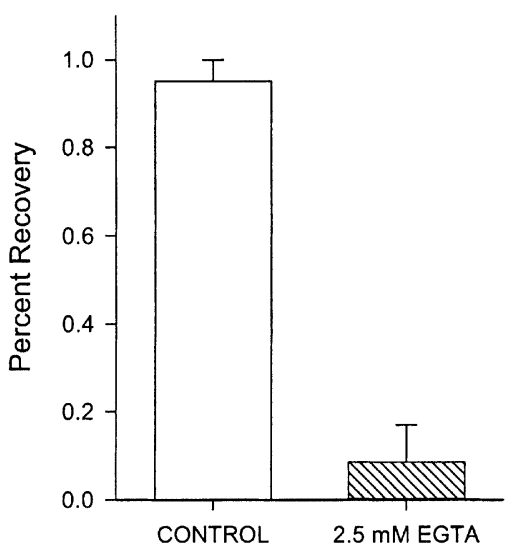

FIG. 5. Rapid refilling of synaptic ribbon. A. The $\Delta C_{m}$ resulting from a paired pulse stimulation paradigm with control internal solution. Each depolarization is $150 \mathrm{~ms}$ in duration separated by a 200-ms interval during which capacitance was measured. B. Same experimental protocol as in A except with the $2.5 \mathrm{mM}$ EGTA-con-

from adaptation. To test both of these ideas, we exploited our ability to study hair cell exocytosis and single-unit afferent fiber activity in the same species. We measured in vivo the time course of sound-evoked short-term adaptation and its recovery. Acoustic stimuli were presented once per second and peristimulus time histograms were constructed from singleunit activity recorded in the chick cochlear nerve. A 100-ms tone burst elicits a characteristic discharge pattern (Fig. 6A) that adapted in this set of experiments with an average time constant of $18.5 \pm 0.8 \mathrm{~ms}$ $(n=9)$. Sound-evoked short-term adaptation was essentially complete after $50 \mathrm{~ms}$ of stimulation. A taining internal solution. C. Comparison of recovery of readily releasable pool with and without $2.5 \mathrm{mM}$ EGTA in the internal solution. On average, the amplitude of the first pulse in the control experiment was $25.8 \pm 7.7 \mathrm{fF}(n=3)$, and with $2.5 \mathrm{mM}$ EGTA the amplitude of the first pulse was $26.2 \pm 5.6 \mathrm{fF}(n=4)$.

paired pulse paradigm was utilized to examine the time course of recovery from this adaptation. The recovery interval was varied in steps from 5 to $320 \mathrm{~ms}$. Recovery from adaptation increased as the interval between tone bursts increased (Fig. 6A). The maximum spike rate resulting from the two stimuli was compared (Fig. 6B). Recovery of the maximum spike rate from short-term adaptation proceeded with a time constant of $69 \mathrm{~ms}(n=9)$ being $95 \%$ recovered at $\sim 210 \mathrm{~ms}$. Thus, the time needed to adapt and recover nerve discharge at this synapse was similar to the time required to exhaust and refill the hair cell readily releasable pool with vesicles. 
A

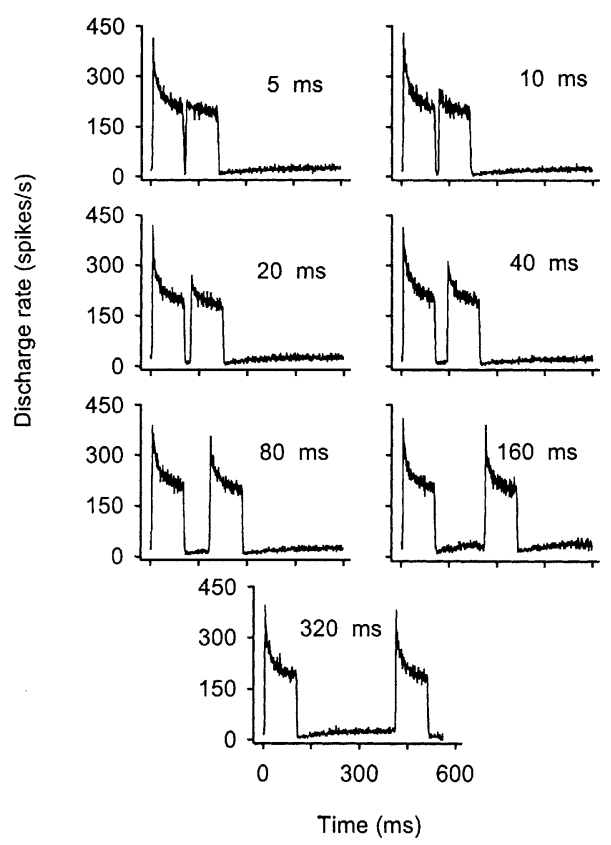

B

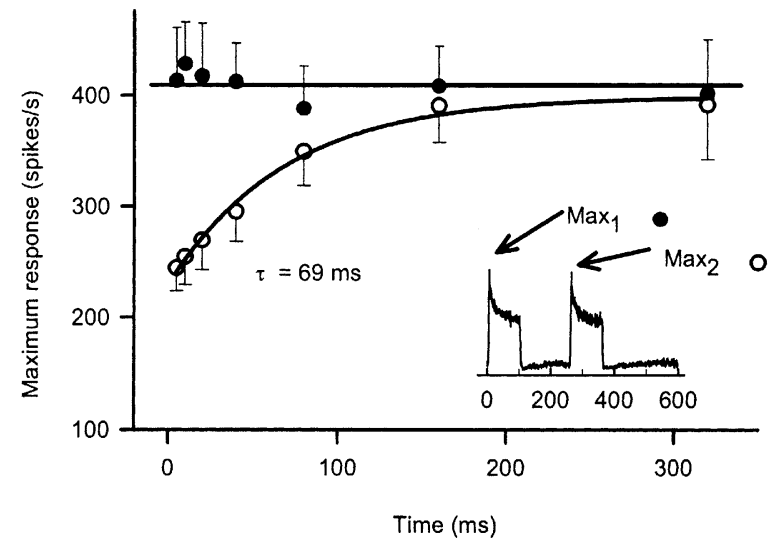

C

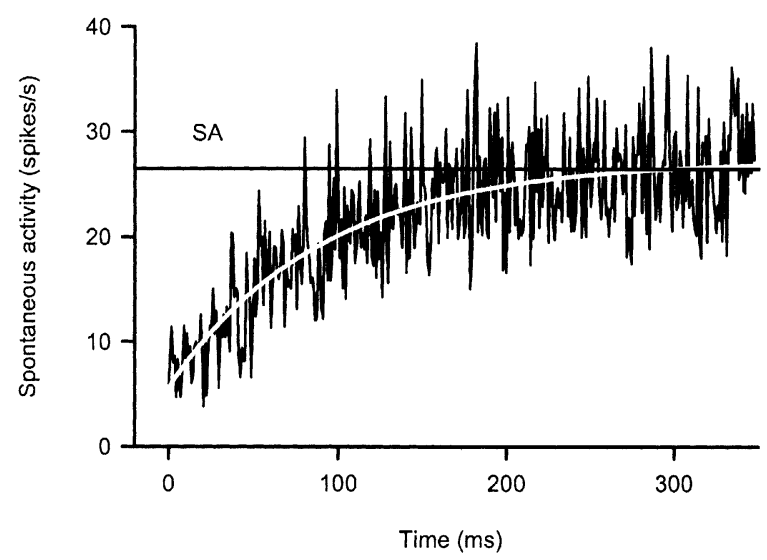

Auditory nerve fibers exhibit spontaneous activity. The cellular basis for this activity has been debated. Several lines of evidence suggest that spontaneous activity results from the release of neurotransmitter
FIG. 6. Recovery of sound-evoked and spontaneous cochlear nerve activity from short-term adaptation. A. Average PSTH histograms across 9 single units for 7 different interstimulus intervals. B. Maximum response rate for both first and second stimulus is plotted versus interstimulus interval (see inset). Maximum response rate of the first is constant, whereas that of the second recovers with a time constant of $69 \mathrm{~ms}$. C. The spontaneous activity after the second tone burst, for the 5-, 10-, 20-, and 40-ms intervals were averaged. The rate of spontaneous activity recovers with a time constant of $97 \mathrm{~ms}$.

rather than simply spontaneous electrical excitation of the nerve fiber alone (Manley and Robertson 1976; Siegel and Relkin 1987). Consistent with this view, the rate of spontaneous activity is inhibited following stimulation that results in adaptation (Fig. 6A). The spontaneous activity after the second tone burst, for the 5-, 10-, 20-, and 40-ms intervals in Figure 6A, was averaged to reveal the time course of spontaneous activity recovery. The recovery time constant was 97 ms (Fig. 6C). The spontaneous activity following the first tone burst in the 320-ms interval of Figure 6A was also analyzed. The recovery of this activity exhibited a time constant of $90 \mathrm{~ms}$. These findings suggest that spontaneous activity in the auditory nerve results from the release of neurotransmitter but, more specifically from the release of vesicles maintained in the readily releasable pool.

\section{DISCUSSION}

The evidence presented here supports the notion that the exhaustion and replenishment of the readily releasable pool mediates short-term auditory nerve adaptation and recovery from adaptation. A fast, or "readily releasable," and a slow kinetic component of exocytosis are observed in chick tall hair cells (Fig. 2). Differential sensitivity to calcium buffering conditions suggests that spatially distinct pools of vesicles (Fig. 4) mediate these two distinct exocytic components. Recovery of the readily releasable pool is fast and blocked by the slow calcium buffer EGTA (Fig. 5). Adaptation and recovery from adaptation of sound-evoked chick cochlear nerve discharges, as well as spontaneous activity, are also fast and follow time courses similar to the exhaustion and recovery of the readily releasable pool (Fig. 6). Thus, we posit that, at this synapse, rapid recovery from short-term adaptation depends on the timely replenishment with vesicles of the readily releasable pool.

\section{Anatomical basis of releasable pools}

The concept of functional pools of releasable or available vesicles at a synapse is well established (Neher 1998), and pools vary in both size and number 
from synapse to synapse. The correlation between ribbon synapse anatomy and physiology is perhaps best studied in the retinal bipolar cell of the goldfish (von Gersdorff and Matthews 1994, 1996; von Gersdorff et al. 1998; Burrone et al. 2002). In the chick cochlea, we now have, for the first time, a similar complement of hair cell physiology (reported here) and anatomy (Martinez-Dunst et al. 1997). This permits us to postulate anatomic substrates for the functional vesicle pools.

The $\Delta C_{\mathrm{m}}$ elicited by short pulses saturated at a value of $\sim 37 \mathrm{fF}$ (average of 50-200-ms pulses in Fig. 2C). This corresponds to the fusion of $\sim 1000$ vesicles given a single vesicle capacitance of $0.037 \mathrm{fF}$ (Lenzi et al. 1999). This is strikingly similar to the number of vesicles that we calculated to be tethered to the synaptic or dense bodies in these tall hair cells. The size and number of synaptic ribbons vary tonotopically in the chick cochlea (Martinez-Dunst et al. 1997). Our patch clamp recordings were limited to the neural most tall hair cells located $\sim 0.5-1.0 \mathrm{~mm}$ from the apical end of the basilar papilla [corresponding to frequencies around $200 \mathrm{~Hz}$ (Chen et al. 1994; Manley 1996)]. Thus, the typical cell is expected to have approximately 24 dense bodies (synaptic ribbons), each about $100 \mathrm{~nm}$ in diameter (Martinez-Dunst et al. 1997). Each dense body is also assumed to be decorated with $\sim 40$-nm-diameter vesicles via a 20 -nmlong tether, and these vesicles reside in a hexagonally packed array that is about 55\% loaded (Lenzi et al. 1999). Based on these assumptions, we calculated (see Material and Methods) each dense body to have approximately 41 vesicles and each tall hair cell to have a total of approximately 984 vesicles tethered to its synaptic ribbons. Thus, the vesicles tethered at the release sites can account for the readily releasable pool.

The calcium buffer experiments further support this notion. The binding properties of the two calcium buffers predict that the readily releasable pool of vesicles lies between 14-nm ( $\left.\lambda_{2.5 B A P T A}\right)$ and $300-$ $\mathrm{nm}\left(\lambda_{\text {2.5EGTA }}\right)$ distance from the sites of calcium influx (Fig. 4A). This distance is consistent with the expected diameter of a tall hair cell dense body decorated with synaptic vesicles (100-nm dense body diameter plus two 20-nm tethers and two 40-nm synaptic vesicles). Taken together, the size and sensitivity to calcium buffers of the readily releasable pool strongly suggests that in chick cochlear tall hair cells this functional pool is accounted for by those vesicles tethered to the synaptic ribbon.

The corollary of these results is that the second slowly activated pool of vesicles resides beyond the ribbon and reflects the recruitment of cytoplasmic vesicles to release sites for exocytosis (Lenzi et al. 1999, 2002). This second kinetic component is sen- sitive to the slow calicum buffer and suggests a dependence on longer-distance calcium signaling (Moser and Beutner 2000). Three possible mechanisms could explain the slow kinetics: (1) mobilization of vesicles from the cytoplasm to the ribbon where they subsequently gain release competency; (2) fusion of release-ready vesicles at sites that are far from calcium channels (Neher 1998); or (3) fusion of release-ready vesicles close to the calcium channels that have two different affinity receptors for calcium (Goda and Stevens 1994; Wu and Borst 1999). The observation that the same pharmacological manipulation that blocked the recovery of the readily releasable pool also blocked the slow kinetic component supports the notion that sustained release of neurotransmitter at this synapse is mediated by mobilization of cytoplasmic vesicles to the synaptic ribbon. Accordingly, the initial slope of the slow component, $\sim 400 \mathrm{fF} / \mathrm{s}$ (Fig. $4 \mathrm{~B}$ ), is more than fast enough to refill the readily releasable pool of $\sim 40 \mathrm{fF}$ in $200 \mathrm{~ms}$ or less.

The calculated number of ribbon-tethered vesicles combined with the results of the buffer experiments suggest that vesicles tethered to the synaptic ribbons most likely define the readily releasable pool and that refilling of the readily releasable pool relies on the rapid recruitment of vesicles from the cytoplasm to reload the ribbon. Spike-rate adaptation and subsequent recovery in the cochlear nerve have kinetics similar to those of the readily releasable pool. Thus, we extend previous hypotheses to suggest that adaptation results from the vesicle depletion of the synaptic ribbon and that rapid recovery from short-term adaptation depends on the timely replenishment of the ribbon with vesicles. Such rapid vesicle dynamics on the synaptic ribbon likely has physiological importance for maintaining the auditory system's ability to faithfully report the onset of sounds in a dynamic acoustic environment.

\section{Function of synaptic ribbon}

The exact contribution of the synaptic ribbon to exocytosis is not known, but is likely important for both tonic and phasic neurotransmitter release. The image of a ribbon fully loaded with readily releasable vesicles suggests an active mechanism, some sort of "conveyor belt," to shuttle vesicles downward toward docking/release sites. This idea appeared to provide a mechanism for sustaining high release rates (Parsons et al. 1994). Despite the intuitive appeal of the ribbon as a conveyor belt for actively moving vesicles toward their docking and release sites (Lenzi and von Gersdorff 2001; von Gersdorff 2001), contrary evidence continues to accumulate (Parsons and Sterling 2003). Our pres- 
ent results argue against vesicle transport. The fast component of exocytosis saturates in $<50 \mathrm{~ms}$ and likely reflects the fusion of synaptic vesicles tethered to the synaptic ribbon. For such exocytosis to be mediated by a conveyor belt mechanism, the release-ready vesicles tethered at the farthest sites from the plasmalemma would need to be transported at a rate of $>5.5 \mu \mathrm{m} / \mathrm{s}$. This is at least twice the speed supported by the fastest known molecular motors (Gilbert 2001).

\section{Comparison of synaptic ribbon emptying and refilling kinetics}

Hair cell exocytosis is fast. Rate constants for vesicle fusion of the readily releasable pool triggered by depolarization range from $>20 \mathrm{~s}^{-1}$ in chick tall hair cells (lower limit estimated from data presented here) to $100 \mathrm{~s}^{-1}$ for mouse inner hair cells (Moser and Beutner 2000). Exocytosis of the readily releasable pool by rod bipolar cell appears to be equally fast or faster $\left(650 \mathrm{~s}^{-1}\right.$; Mennerick and Matthews 1996; Neves and Lagnado 1999). However, such comparisons are complicated by differences across ribbon synapses in the anatomical substrate of the readily releasable pool as defined by the first kinetic component of exocytosis (see Table 1). In the rod bipolar cell, the readily releasable pool is thought to correspond only to the first row of vesicles on either side of its planar ribbon structure, whereas in the chick hair cell the readily releasable pool likely corresponds to all the vesicles tethered to the ribbon. Thus, the actual rate of ribbon emptying in the rod bipolar cell is much slower than the hair cell, only $8 \mathrm{~s}^{-1}$. In mouse, the anatomical substrate of the readily releasable pool is presently unknown, as detailed quantitative ultrastructure of the neonatal mouse hair cell release site is not available. It is therefore unclear in mouse whether the fast kinetic component corresponds to the vesicles tethered to the entire ribbon or only the first row of vesicles docked to the plasmlemma. The situation with mouse cochlear hair cells contrasts with the frog saccular hair cell where exquisite anatomical studies exist (Lenzi et al. 1999, 2002), but comparable physiological recordings are yet to be reported.

The refilling rates of the readily releasable pool in hair cells are also fast. Here we report that the chick readily releasable pool is essentially refilled in less than $200 \mathrm{~ms}$ (95\% recovered; Fig. 5). The comparable measure for mouse is $\sim 420 \mathrm{~ms}$ (Moser and Beutner 2000). This is in contrast to the retinal bipolar cell where even the fastest exocytic component recovers relatively slowly $(\tau=600 \mathrm{~ms}$; Gomis et al. 1999) and putative reloading of the ribbon is even slower ( $\sim 20 \mathrm{sec}$; von Gersdorff and Mat- thews 1997). Thus, while a comparison of exocytic rates between ribbon synapses may be equivocal, recovery of the readily releasable vesicle pool in cochlear hair cells is faster than readily releasable pool recovery in retinal bipolar cells. This functional difference may reflect different physiological requirements for the processes of hearing and vision and raises the possibility of underlying molecular differences between auditory and visual synaptic ribbons.

\section{Limitations of the present study}

The ability to compare the kinetics of hair cell synaptic vesicle fusion and single cochlear nerve unit activity in the same animal model promises a powerful approach to understanding synaptic mechanisms of the cochlear hair cell-afferent fiber synapse. However, experimental conditions differed between the two recording paradigms, and their potential impact on the interpretation of the data warrants discussion, (i) Temperature - The in vivo recordings of nerve activity were done at body temperature $\left(41^{\circ} \mathrm{C}\right), \sim 15^{\circ} \mathrm{C}$ warmer than the temperature of the in vitro capacitance measurements. Although not known for the cochlear hair cellafferent fiber synapse, the $Q_{10}$ of release kinetics at other synapses is 3 (Katz and Miledi 1965; Barrett and Stevens 1972; Isaacson and Walmsley 1995) and would predict as much as a fivefold increase in the hair cell exocytic kinetics in vivo. (ii) Endogenous calcium buffer - Our "control" intracellular buffer condition was $0.2 \mathrm{mM}$ EGTA. This is similar to the equivalent endogenous buffer concentration of $\sim 0.1 \mathrm{mM}$ EGTA reported for exocytosis in mouse cochlear hair cells (Moser and Beutner 2000) but differs from the $\sim 1 \mathrm{mM}$ BAPTA observed for calcium-activated potassium channels in the frog saccular hair cells (Roberts 1993). (iii) Waveform of membrane depolarization - Nerve discharges were evoked by tonal stimuli. The acoustic stimuli generate receptor potentials that might differ from the step changes in membrane potential utilized in the patch clamp experiments. The amplitude of square wave depolarizations used to trigger exocytosis in vitro was chosen to maximize calcium influx (Spassova et al. 2001) and thus saturate rapid exocytosis elicited via depolarization. However, little is known in the chick about sound-evoked receptor potentials. If similar to other species, then both half-wave rectification and/or low-pass filtering of the receptor potential is expected. Given appropriate frequency and intensity stimulation, either transduction property can yield a square wave or steplike receptor potential (Russell and Sellick 1978; Holton and Weiss 1983). 


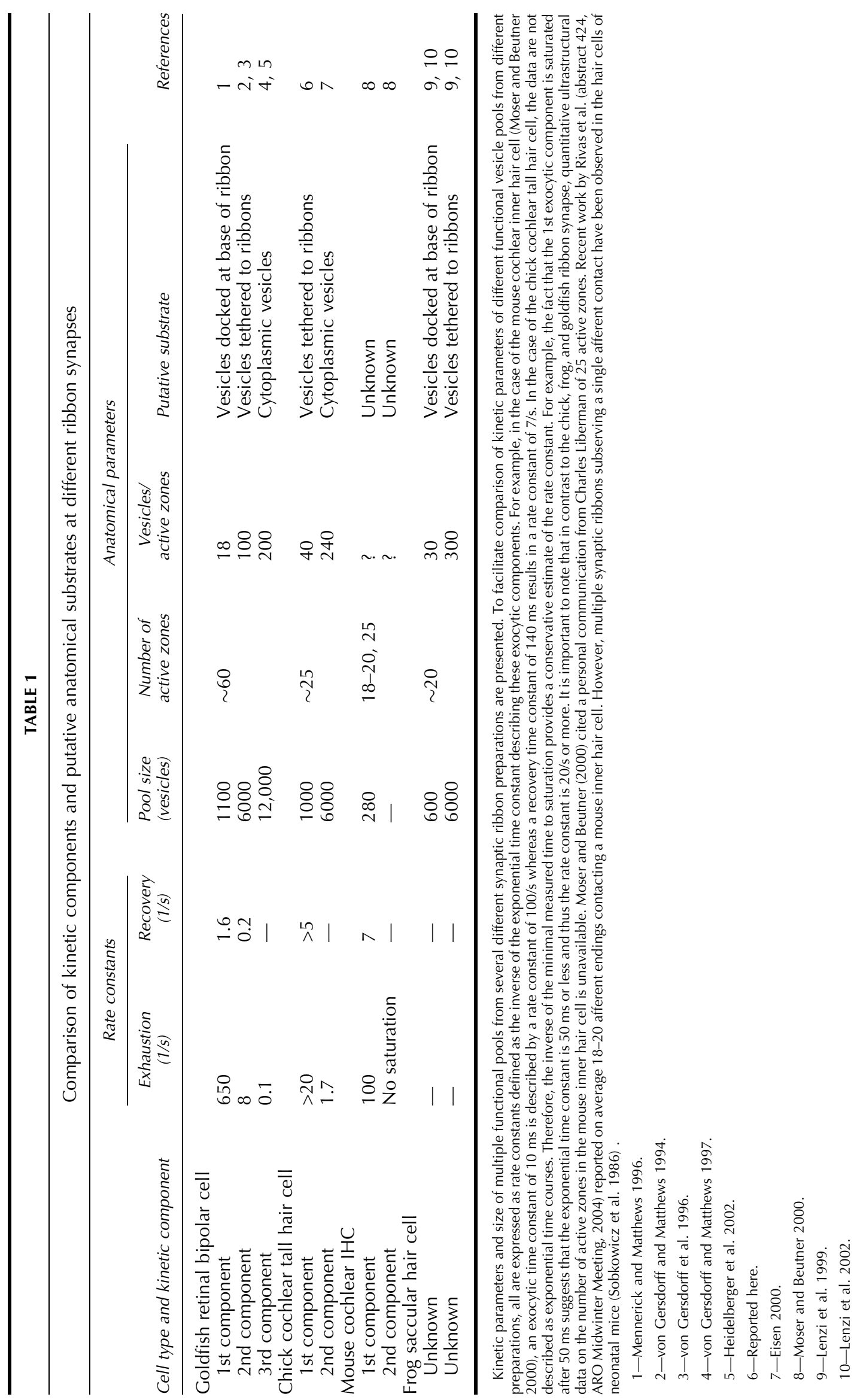


Behavioral significance of rapid reloading of the synaptic ribbons with vesicles

The kinetic difference between retinal bipolar cells and auditory hair cells for reloading vesicles at the synaptic ribbon is striking (hair cell is about tenfold faster). These differences may result from the unique functional demands of the auditory system and visual system. A large store of readily releasable vesicles insures the rapid and reliable release of synaptic vesicles given stochastic but inherently slow exocytic processes (Almers 1994). Such a large store of vesicles is tethered to the ribbon, and the maintenance of the store is essential for high-fidelity neurotransmission at sound onset. Conversely, depletion of this vesicle pool results in adaptation and serves to conserve bandwidth by reducing the synaptic drive from ongoing stimuli. However, since most sounds requiring attention in a natural soundscape are transient, faithfully reporting the onset of a new sound depends on a prompt recovery from adaptation by rapidly reloading the synaptic ribbon with vesicles. Perhaps the rapidity with which the cochlear hair cell synaptic ribbon reloads with release-ready vesicles portends the evolutionary importance of the auditory system in detecting potentially threatening stimuli.

\section{ACKNOWLEDGMENTS}

We thank Graham Ellis-Davies for the use of equipment, Marc D. Eisen for help with the figures, and Phil Haydon for helpful discussions. This work was supported by NIH DC00710, the Pennsylvania Lions Hearing Research Foundation (JCS), NIH DC03763, and Sloan Research Fellow (TDP).

\section{REFERENCES}

Almers W. Synapses. How fast can you get? Nature 367:682-683, 1994.

Attneave F. Some informational aspects of visual perception. Psychol. Rev. 61:183-193, 1954.

BARLOW HB. Possible principles underlying the transformations of sensory messages. In: Rosenblith WA (ed) Sensory Communication. MIT Press, Cambridge, MA, pp 217-234, 1961.

Barrett EF, StEVEns CF. The kinetics of transmitter release at the frog neuromuscular junction. J. Physiol. 227:691-708, 1972.

Bollmann JH, Sakmann B, Borst JG. Calcium sensitivity of glutamate release in a calyx-type terminal. Science 289:953-957, 2000.

Brenner N, Bialek W, De Ruyter van Steveninck R. Adaptive rescaling maximizes information transmission. Neuron 26:695-702, 2000.

Burrone J, Neves G, Gomis A, Cooke A, Lagnado L. Endogenous calcium buffers regulate fast exocytosis in the synaptic terminal of retinal bipolar cells. Neuron 33:101-112, 2002.
Carandini M, Ferster D. A tonic hyperpolarization underlying contrast adaptation in cat visual cortex. Science 276:949-952, 1997.

Chen L, Salvi R, Shero M. Cochlear frequency-place map in adult chickens: intracellular biocytin labeling. Hear Res. 81:130-136, 1994.

Chimento TC, Schreiner CE. Adaptation and recovery from adaptation in single fiber responses of the cat auditory nerve. J. Acoust. Soc. Am. 90:263-273, 1991.

Chung S, Li X, Nelson SB. Short-term depression at thalamocortical synapses contributes to rapid adaptation of cortical sensory responses in vivo. Neuron 34:437-446, 2002.

Debus K, Hartmann J, Kilic G, Lindau M. Influence of conductance changes on patch clamp capacitance measurements using a lock-in amplifier and limitations of the phase tracking technique. Biophys. J. 69:2808-2822, 1995.

EISEN MD. Neurotransmitter release at the chick cochlear hair cell afferent synapse. Ph.D. Dissertation. University of Pennsylvania, Philadelphia, PA, 2000.

Eisen MD, Spassova M, Parsons TD. Large releasable pool of synaptic vesicles in chick cochlear hair cells. J. Neurophysiol. 91:2422-2429, 2004.

Fain GL, Matthews HR, Connwall MC, Koutalos Y. Adaptation in vertebrate photoreceptors. Physiol. Rev. 81:117-151, 2001.

Forsythe ID, Tsujimoto T, Barnes-Davies M, Cuttle MF, Takahashi $\mathrm{T}$. Inactivation of presynaptic calcium current contributes to synaptic depression at a fast central synapse. Neuron 20:797$807,1998$.

Fuchs PA, NAGAI T, Evans MG. Electrical tuning in hair cells isolated from the chick cochlea. J. Neurosci. 8:2460-2467, 1988.

Fuchs PA, Evans MG, Murrow BW. Calcium currents in hair cells isolated from the cochlea of the chick. J. Physiol. (Lond.) 429:553-568, 1990.

Furukawa T, Kuno M, Matsuura S. Quantal analysis of a decremental response at hair cell-afferent fibre synapses in the goldfish sacculus. J. Physiol. 322:181-195, 1982.

GilbERT SP. High-performance fungal motors. Nature 414:597-598, 2001.

GILLIS KD. Admittance-based measurement of membrane capacitance using the EPC-9 patch-clamp amplifier. Pflugers Arch. 439:655-664, 2000.

Goda Y, Stevens CF. Two comonents of transmitter release at a central synapse. Proc. Natl. Acad. Sci. USA 91:12942-12946, 1994.

Gomez G, Atema J. Temporal resolution in olfaction II: time course of recovery from adaptation in lobster chemoreceptor cells. J. Neurophysiol. 76:1340-1343, 1996.

Gomis A, Burrone J, Lagnado L. Two actions of calcium regulate the supply of releasable vesicles at the ribbon synapse of retinal bipolar cells. J. Neurosci. 19:6309-6317, 1999.

Hamill OP, Marty A, Neher E, Sakmann B, Sigworth FJ. Improved patch-clamp techniques for high-resolution current recording from cells and cell-free membrane patches. Pflugers Arch. 391:85-100, 1981

Harris DM, Dallos P. Forward masking of auditory nerve fiber responses. J. Neurophysiol. 42:1083-1107, 1979.

Heidelberger R, Sterling P, Matthews G. Roles of ATP in depletion and replenishment of the Releasable pool of synaptic vesicles. Journal of Neurophysiology 88: 98-106, 2002.

Holton T, Weiss TF. Receptor potentials of lizard cochlear hair cells with free-standing stereocilia in response to tones. J. Physiol. 345:205-240, 1983.

Horrigan FT, BOOKMan RJ. Releasable pools and the kinetics of exocytosis in adrenal chromaffin cells. Neuron 13:1119-1129, 1994. 
HudSPETH AJ, LewIS RS. Kinetic analysis of voltage- and ion-dependent conductances in saccular hair cells of the bull-frog, Rana catesbeiana. J. Physiol. (Lond.) 400:237-274, 1998.

IsAACSON JS, WALMSLEY B. Counting quanta: direct measurements of transmitter release at a central synapse. Neuron 15:875-884, 1995.

JAVEL E. Long-term adaptation in cat auditory nerve fiber responses. J. Acoust. Soc. Am. 99:1040-1052, 1996.

Katz B, Miledi R. The effect of temperature on the synaptic delay at the neuromuscular junction. J. Physiol. 181:656-670, 1965 .

KIANG NYS. Discharge patterns of single fibers in the cat's auditory nerve. MIT Press, Cambridge, MA, 1965.

KIM KJ, Rieke F. Slow $\mathrm{Na}^{+}$inactivation and variance adaptation in salamander retinal ganglion cells. J. Neurosci. 23:1506-1516, 2003.

Koutalos Y, Yau KW. Regulation of sensitivity in vertebrate rod photoreceptors by calcium. Trends Neurosci. 19:73-81, 1996.

LENZI D, vON GERSDORFF H. Structure suggests function: the case for synaptic ribbons as exocytotic nanomachines. Bioessays 23:831840, 2001.

Lenzi D, Runyeon JW, Crum JW, Ellisman MH, Roberts WM. Synaptic vesicle populations in saccular hair cells reconstructed by electron tomography. J. Neurosci. 19:119-132, 1999.

Lenzi D, Crum J, Ellisman MH, Roberts WM. Depolarization redistributes synaptic membrane and creates a gradient of vesicles on the synaptic body at a ribbon synapse. Neuron 36:649-659, 2002.

Lindau M, Neher E. Patch-clamp techniques for time-resolved capacitance measurements in single cells. Pflugers Arch. 411: 137-146, 1988.

Manley GA, Robertson D. Analysis of spontaneous activity of auditory neurones in the spiral ganglion of the guinea-pig cochlea. J. Physiol. 258:323-336, 1976.

Manley GA. Ontogeny of frequency mapping in the peripheral auditory system of birds and mammals: A critical review. Aud. Neurosci. 3:199-214, 1996.

Martinez-Dunst C, Michaels RL, Fuchs PA. Release sites and calcium channels in hair cells of the chick's cochlea. J. Neurosci. 17:9133-9144, 1997.

Mennerick S, Matthews G. Ultrafast exocytosis elicited by calcium current in synaptic terminals of retinal bipolar neurons. Neuron 17:1241-1249, 1996.

Moser T, Beutner D. Kinetics of exocytosis and endocytosis at the cochlear inner hair cell afferent synapse of the mouse. Proc. Natl. Acad. Sci. USA 97:883-888, 2000.

NeHER E. Concentration profiles of intracellular calcium in the presence of a diffusible chelator. Exp. Brain Res. 14:80-96, 1986.

NeHER E. Vescile pools and $\mathrm{Ca}^{2+}$ microdomains: new tools for understanding their roles in neurotransmitter release. Neuron 20:389-399, 1998.

NeHer E, Zucker RS. Multiple calcium-dependent processes related to secretion in bovine chromaffin cells. Neuron 10:21-30, 1993.

Neves G, Lagnado L. The kinetics of exocytosis and endocytosis in the synaptic terminal of goldfish retinal bipolar cells. J. Physiol. (Lond.) 515:181-202, 1999.

OHMORi H. Studies of ionic currents in the isolated vestibular hair cell of the chick. J. Physiol. (Lond.) 350:561-581, 1984.

Palmer MJ, Hull C, Vigh J, von Gersdorff H. Synaptic cleft acidification and modulation of short-term depression by exocytosed protons in retinal bipolar cells. J. Neurosci. 23:11332-11341, 2003.

Parsons TD, Sterling P. Synaptic ribbon: Conveyor belt or safety belt? Neuron 37:379-382, 2003.
Parsons TD, Lenzi D, Almers W, Roberts WM. Calcium-triggered exocytosis and endocytosis in an isolated presynaptic cell: capacitance measurements in saccular hair cells. Neuron 13:875-883, 1994.

Parsons TD, Coorssen JR, Horstmann H, Lee AK, Tse FW, Almers W. The last seconds in the life of a secretory vesicle. Cold Spring Harbor, Symp. Quant. Biol. 60:389-396, 1995.

Rebillard G, Rubel EW. Electrophysiological study of the maturation of auditory responses from the inner ear of the chick. Brain Res. 229:15-23, 1981.

RoBERTs WM. Spatial calcium buffering in saccular hair cells. Nature 363:74-76, 1993.

RoBerTs WM. Localization of calcium signals by a mobile calcium buffer in frog saccular hair cells. J. Neurosci. 14:3246-3262, 1994.

Rodriguez-Contreras A, Nonner W, YAMOAH EN. $\mathrm{Ca}^{2+}$ transport properties and determinants of anomalous mole fraction effects of single voltage-gated $\mathrm{Ca}^{2+}$ channels in hair cells from bullfrog saccule. J. Physiol. 538:729-745, 2002.

Russell IJ, Sellick PM. Intracellular studies of hair cells in the mammalian cochlea. J. Physiol. (Lond.) 284:261-290, 1978.

Saunders JC, Coles RB, Gates GR. The development of auditory evoked responses in the cochlea and cochlear nuclei of the chick. Brain Res. 63:59-74, 1973.

Saunders JC, Doan DE, Poje CP, Fisher KA. Cochlear nerve activity after intense sound exposure in neonatal chicks. J. Neurophysiol. 76:770-787, 1996.

Schikorski T, Stevens CF. Morphological correlates of functionally defined synaptic vesicle populations. Nat. Neurosci. 4:391-395, 2001.

SchneE ME, Ricci AJ. Biophysical and pharmacological characterization of voltage-gated calcium currents in turtle auditory hair cells. J. Physiol. 549:697-717, 2003.

Schneggenburger R, Neher E. Intracellular calcium dependence of transmitter release rates at a fast central synapse. Nature 406:889-893, 2000.

SiegEL JH, ReLkin EM. Antagonistic effects of perilymphatic calcium and magnesium on the activity of single cochlear afferent neurons. Hear Res. 28:131-147, 1987.

Sмiтн CB, Betz WJ. Simultaneous independent measurement of endocytosis and exocytosis. Nature 380:531-534, 1996.

SмIтH RL. Short-term adaptation in single auditory nerve fibers: some poststimulatory effects. J. Neurophysiol. 40:1098-1111, 1977.

Sobkowicz HM, Rose JE, Scott GL, Levenick CV. Distribution of synaptic ribbions in the developing organ of Corti. J. Neurocytol. 15: 693-714, 1986.

Spassova M, Eisen MD, Saunders JC, Parsons TD. Chick cochlear hair cell exocytosis mediated by dihydropyridine-sensitive calcium channels. J. Physiol. (Lond.) 535:689-696, 2001.

Thomas P, Wong JG, LeE AK, Almers W. A low affinity $\mathrm{Ca}^{2+}$ receptor controls the final steps in peptide secretion from pituitary melanotrophs. Neuron 11:93-104, 1993.

vON Gersdoff H. Synaptic ribbons: versatile signal transducers. Neuron 29:7-10, 2001.

von Gersdorff H, Matthews G. Dynamics of synaptic vesicle fusion and membrane retrieval in synaptic terminals. Nature 367:735739, 1994.

von Gersdorff H, Matthews G. Calcium-dependent inactivation of calcium current in synaptic terminals of retinal bipolar neurons. J. Neurosci. 16:115-122, 1996.

von Gersdorff H, Matthews G. Depletion and replenishment of vesicle pools at a ribbon-type synaptic terminal. J. Neurosci. 17:1919-1927, 1997.

von Gersdorff H, Sakaba T, Berglund K, Tachibana M. Submillisecond kinetics of glutamate release from a sensory synapse. Neuron 21:1177-1188, 1998. 
Westerman LA, Smith RL. Rapid and short-term adaptation in auditory nerve responses. Hear Res. 15:249-260, 1984.

Wu LG, Bonst JG. The reduced release probability of releasable vesicles during recovery from short-term synaptic depression. Neuron 23:821-832, 1999.
Wu LG, SAGgau P. Presynaptic inhibition of elicited neurotransmitter release. Trends Neurosci. 20:204-212, 1997.

Yates GK, Robertson D, Johnstone BM. Very rapid adaptation in the guinea pig auditory nerve. Hear Res. 17:1-12, 1985.

ZidANIC M, Fuchs PA. Kinetic analysis of barium currents in chick cochlear hair cells. Biophys. J. 68:1323-1336, 1995. 